\title{
THE VALUE OF SCREENING TESTS IN THE DETECTION OF PROSTATE CANCER. PART II: RETROSPECTIVE ANALYSIS OF FREE/TOTAL PROSTATE-SPECIFIC ANALYSIS RATIO, AGE- SPECIFIC REFERENCE RANGES, AND PSA DENSITY*
}

\author{
CHRIS H. BANGMA, M.D., RIES KRANSE, ING, BERT G. BLIJENBERG, PH.D., \\ AND FRITZ H. SCHRÖDER, M.D., PH.D.
}

\begin{abstract}
Objectives. The ratio between free and total prostate-specific antigen (PSA) in serum ( $\mathrm{F} / \mathrm{T}$ ratio) was shown to improve the specificity of total serum PSA for the detection of prostate carcinoma in selected populations. In this study, the value of the F/T ratio for screening of prostate cancer was compared with that of age-specific reference ranges for PSA and PSA density (PSAD) by a simulation experiment.

Methods. In 1726 men between 55 and 76 years old, 67 prostate carcinomas were detected by application of digital rectal examination (DRE), transrectal ultrasonography (TRUS), and total serum PSA. A serum PSA of $4.0 \mathrm{ng} / \mathrm{mL}$ or more, an abnormal DRE, or an abnormal TRUS were the indications to perform 308 biopsies. A simulation was performed in which an F/T ratio of 0.20 (ProStatus PSA Free/Total), age-specific PSA reference ranges, and a PSAD of $0.12 \mathrm{ng} / \mathrm{mL} / \mathrm{cc}$ were used to study their capability to increase the specificity of total serum PSA in predicting prostate biopsy results.

Results. Using age-specific PSA reference ranges and DRE as indicators for biopsy, a reduction of $37 \%$ (113) of biopsies would have been obtained with a loss of detected cancers of $12 \%$ (11). For the use of PSAD and DRE, these numbers were $28 \%(96)$ and $11 \%(7)$, respectively. Application of a serum PSA of $4.0 \mathrm{ng} / \mathrm{mL}$ or more and an F/T ratio of 0.20 or less and an abnormal DRE as indicators for biopsy would reduce the number of biopsies by $37 \%(112)$ and the number of detected cancers by $11 \%(7)$. The biopsy to prostate cancer ratio of these simulations varied between 3.3 and 3.6. Minimal loss of cancer detection of $3 \%$ (2) with a reduction in the number of biopsies of $17 \%(53)$ is obtained when TRUS is omitted from the screening protocol. Selecting men by a total serum PSA value of $2.0 \mathrm{ng} / \mathrm{mL}$ for further diagnostic workup by TRUS and DRE would have reduced the number of biopsies by $30 \%$ (102), and the number of cancers detected by $6 \%$ (4).

Conclusions. The most cost-effective protocol for screening prostate carcinoma appears to be prescreening by total serum PSA. The F/T ratio might be used to detect carcinomas in the PSA range below $4.0 \mathrm{ng} / \mathrm{mL}$, but the best threshold remains to be assessed. LROLOGY ${ }^{\circledR}$ 46: 779-784, 1995.
\end{abstract}

$S^{\prime}$ creening for prostate cancer $(\mathrm{PC})$ is usually performed by prostate-specific antigen (PSA) and digital rectal examination (DRE); transrectal ultrasonography (TRUS) can be added for lesion detection and prostate volumetry. Selection of candidates for prostate biopsy is complicated by the fact that all screening modalities lack sufficient specificity. This results in a high ratio between the number of biopsies and the number of detected carcinomas. In most screening studies, overall about five biopsies are needed to detect one carcinoma. ${ }^{1-5}$

*This study was supported by grants from "Europe against Cancer," the Dutch Cancer Society (KWF), and the Prevention Fund of the Netherlands, as well as by an educational grant of Wallac Oy, Finland.

From the Department of Urology and of Clinical Chemistry, Academic Hospital, Rotterdam, The Netherlands

Reprint requests: Chris H. Bangma, M.D., Department of

Urology, Academic Hospital, Rotterdam, The Netherlands

Submitted: September 9, 1995, accepted: October 16, 1995
Several additional parameters, such as prostate volume and age, have been analyzed to reduce this ratio, without trying to limit the number of carcinomas. $^{6-9}$

The free to total serum PSA ratio (F/T ratio) may represent a new parameter to increase the specificity of total serum PSA to detect PC in selected patients ${ }^{10-12}$ and in a screening population. ${ }^{13}$

In this study, a simulated case selection for biopsy was performed in a well-defined screening population to illustrate the value of $F / T$ ratio, agespecific PSA reference ranges, ${ }^{14}$ and PSA density (PSAD) ${ }^{15}$ for the detection of PC.

\section{MATERIAL AND METHODS}

In 1726 men from the general population, aged between 55 and 76 years, serum PSA (DELFIA ProStatus PSA Free/Total; Wallac Oy, Finland), and TRUS, were performed. Serum sample collection and storage, PSA tests used, the study population, screening tools, and biopsy indications were described in a previous publication in this journal ${ }^{13}$ and in separate 


\section{TABLE I. Results of simulated case selection for biopsy, based on the results by screening with PSA, DRE, and TRUS in 1726 men, of whom 67 men with prostate cancer had 308 biopsies (first) line}

\begin{tabular}{clccc}
\hline Prescreen & \multicolumn{1}{c}{ Biopsy Indicator } & $\begin{array}{c}\text { Reduction of } \\
\text { Biopsies (\%) } \\
\text { (SE) }\end{array}$ & $\begin{array}{c}\text { Loss of } \\
\text { PC (\%) } \\
\text { (SE) }\end{array}$ & $\begin{array}{c}\text { Overall } \\
\text { Bx/PC }\end{array}$ \\
\hline- & PSA > 4, DRE, TRUS & - & - & 4.6 \\
- & PSA > 4, DRE & $17(2.1)$ & $3(2.1)$ & 3.9 \\
PSA > 2, & PSA > 4, DRE, TRUS & $30(2.6)$ & $6(2.9)$ & 3.4 \\
PSA $>2$, & PSA > 4, DRE & $36(2.8)$ & $6(2.9)$ & 3.1 \\
PSA-age & PSA > 4, DRE, TRUS & & $39(6.0)$ & \\
- & PSA-age, DRE & $37(2.8)$ & $12(4.0)$ & 3.3 \\
- & PSAD, DRE & $28(2.4)$ & $11^{*}(3.8)$ & $3.6^{*}$ \\
- & PSA > 4 AND PSAD, DRE & $39(2.8)$ & $11(3.8)$ & 3.2 \\
- & PSA > 4 AND F/T, DRE & $37(2.8)$ & $11(3.8)$ & 3.3
\end{tabular}

KEY: $B x=$ biopsy; DRE = abnormal result by digital rectal examination; $F / T=$ free/total PSA ratio 0.20 or less; PC $=$ prostate cancer; $P S A>4=$ total serum PSA of 4.0 $\mathrm{ng} / \mathrm{mL}$ or more; PSA-age = total serum PSA larger than age-specific reference range; PSAD = PSA density $0.12 \mathrm{ng} / \mathrm{mL} / \mathrm{cc}$ or more; TRUS =lesion detected by transrectal ultrasound.

* Real incidence of cancers unknown.

TABLE II. Age, prostatic volumes, and PSA values of 1659 benign and 67 participants with prostate cancer

\begin{tabular}{|c|c|c|c|c|c|c|}
\hline & \multicolumn{3}{|c|}{ Benign } & \multicolumn{3}{|c|}{ Prostate Cancer } \\
\hline & No. & Median & Range & No. & Median & Range \\
\hline Age (yr) & 1659 & 64.0 & $54.1-77.0$ & 67 & 66.8 & $55.6-76.2$ \\
\hline Total gland volume & 1565 & 30.5 & $7.7-203.6$ & 64 & 33.0 & $16.3-105.4$ \\
\hline Transition zone volume & 1606 & 9.3 & $0.5-115.0$ & 63 & 10.6 & $3.3-47.2$ \\
\hline Abbott IMx & 792 & 1.2 & $0-33.5$ & 31 & 6.3 & $0.4-93.8$ \\
\hline Hybritech Tandem E & 867 & 1.3 & $0-29.6$ & 36 & 7.1 & $1-156$ \\
\hline DELFIA ProStatus EOM & 1659 & 1.3 & $0.01-34.9$ & 67 & 7.2 & $0.4-165.1$ \\
\hline DELFIA ProStatus FT total PSA & 1659 & 1.2 & $0.01-30.0$ & 67 & 7.6 & $0.5-149.6$ \\
\hline DELFIA ProStatus FT free PSA & 1659 & 0.33 & $0.01-8.4$ & 67 & 0.9 & $0.15-15.6$ \\
\hline
\end{tabular}

studies. ${ }^{16,17}$ Ultrasound-guided random sextant biopsies were performed if the serum PSA level was $4.0 \mathrm{ng} / \mathrm{mL}$ and higher, or if the DRE was abnormal. When hypoechoic lesions were seen by TRUS, biopsy of the lesion was also performed next to sextant biopsies.

Age-specific reference ranges for PSA and $F / T$ ratio were constructed ${ }^{14}$ with the IMx and the ProStatus PSA Free/Total assays, using the 95th percentile upper limit of values (mean value plus 2 standard deviations) in men without prostate cancer, to analyze their capacity to distinguish between tumor and benign conditions. To allow comparison with available literature information, the sera of 188 asymptomatic blood donors aged 20 to 43 years were also assessed. Reference ranges for the age between 44 and 55 years were extrapolated from these results. Grouping by age ranges of 5 years was used to allow for a more continuous spectrum compared with age ranges of 10 years. ${ }^{18}$

Venn diagrams were used to describe the number of biopsies performed, and the number of cancers detected in the population studied and in the simulation procedure. Entry in the various simulations was by a total serum PSA of 4.0 $\mathrm{ng} / \mathrm{mL}$ and more, an abnormal DRE, an F/T ratio smaller than 0.20 , a total serum PSA exceeding the constructed age reference value, and a PSAD value of $0.12 \mathrm{ng} / \mathrm{mL} / \mathrm{cc}$ or more. The $F / T$ ratio threshold of 0.20 was chosen, as this value was in between the median values of 67 men with and 1659 men without PC. ${ }^{11}$ The PSAD threshold was chosen as recommended by Littrup et al., ${ }^{6}$ who optimalized their original threshold of $0.20 \mathrm{ng} / \mathrm{mL} / \mathrm{cc}$ in 1991 to a value of 0.12 $\mathrm{ng} / \mathrm{mL} / \mathrm{cc}$ for use in a screening population. Omitting lesion detection by TRUS in the various simulations excluded 2 men with $P C$, and limited the maximum number of detected carcinomas to 65 . Also a PSA prescreen value of $2.0 \mathrm{ng} / \mathrm{mL}$ was evaluated because of the expected cost-effectiveness. Results of the various simulations have been summarized, in which the standard error (SE) of the calculated reductions in biopsies and detected cancers are depicted (Table I).

\section{RESULTS}

General characteristics of all men are shown in Table II. In 1726 men, 67 cancers were histologically diagnosed by 308 sextant prostate biopsies. There was no significant difference between the median prostate volume of men with and without PC. Therefore, no sampling advantage by biopsy for smaller prostates occurred. ${ }^{19}$

Figure 1A shows the Venn diagram illustrating the distribution of the indications for prostate biopsy in 308 men with abnormal DRE, TRUS, or a serum PSA value of $4.0 \mathrm{ng} / \mathrm{mL}$ or more. In Figure $1 \mathrm{~B}$, the number of cancers found and the biopsy (Bx)/PC ratio (between parentheses) is indicated. The combination of all three screening 
TABLE III. Age-specific PSA reference ranges: indicated are the upper limits (all lower limits are equal to zero)

\begin{tabular}{lcccccc}
\hline & \multicolumn{7}{c}{ Age Range } \\
\cline { 2 - 7 } & $\mathbf{4 0 - 4 9}$ & $\mathbf{5 0 - 5 4}$ & $\mathbf{5 5 - 5 9}$ & $\mathbf{6 0 - 6 4}$ & $\mathbf{6 5 - 6 9}$ & $\mathbf{7 0 - 7 5}$ \\
\hline Oesterling et al. ${ }^{14}$ & 2.5 & 3.5 & & 4.5 & & 6.5 \\
Abbott IMx & 2.8 & 3.5 & 4.0 & 4.7 & 5.4 & 6.3 \\
ProStatus Total & 3.1 & 3.8 & 4.3 & 4.9 & 5.5 & 6.3 \\
ProStatus Free & 0.75 & 0.87 & 0.96 & 1.06 & 1.17 & 1.29 \\
\hline
\end{tabular}

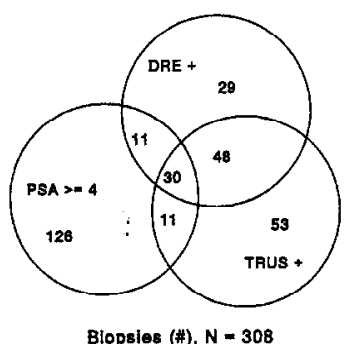

A

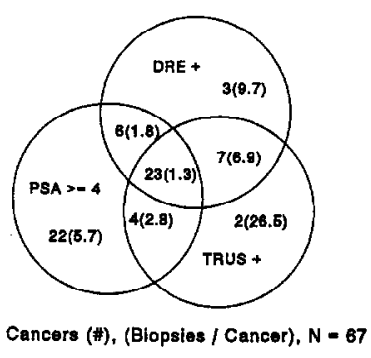

B
FIGURE 1. Venn diagrams illustrating the distribution of the indications for prostate biopsy in 308 men (A), and the number of cancers detected by digital rectal examination, TRUS, and a serum PSA value of 4.0 $n g / m L$ or more (B); between parentheses is noted the ratio between the number of biopsies performed and the number of cancers detected (biopsy/cancer ratio).

modalities led to the lowest, and most effective, $\mathrm{Bx} / \mathrm{PC}$ ratio of 1.3 , while 26.5 biopsies were needed to detect one carcinoma when the indication for biopsy was a hypoechogenic lesion only. Overall the $\mathrm{Bx} / \mathrm{PC}$ ratio was 4.6 .

Table III shows age-specific reference ranges for PSA described by Oesterling et al. ${ }^{14}$ and those of the participants of this study, excluding those men with a detected PC. The reference ranges include $95 \%$ of the serum PSA values per age-group for 1847 men (benign participants and donors) without detectable PC. The correlation coefficient between age and total PSA for all men, including blood donors, was 0.32 , and 0.16 for men aged 50 years or older. For the free PSA (ProStatus Free/Total), these correlations were 0.30 and 0.21 , respectively.

In Figure 2 the detected PCs are indicated in relation to the 95 percentile of the age reference ranges for PSA. Organ-confined tumors $(n=59$, clinically staged) are contrasted with nonorgan confined tumors $(n=7)$, or carcinomas with unknown stage $(n=1)$. A large number of detected prostate carcinomas (39\%, 20 confined, 2 nonconfined, 1 unknown staging) are found within the age-specific reference ranges. The cases are rather equally distributed over the age-groups involved.

\section{F/T RATIO}

Figure 3 shows the simulated case selection for biopsy using a PSA value of $4.0 \mathrm{ng} / \mathrm{mL}$ or more, an abnormal DRE, and an F/T ratio of 0.20 or less as a criterion for biopsy. Of 494 men who entered into this simulation, 263 had biopsies. Of 363 men who had an indication for biopsy based on the F/T ratio of 0.20 or less, only 132 had biopsies according to the study protocol (Fig. 3A). In the PSA range of $4.0 \mathrm{ng} / \mathrm{mL}$ and more, the specificity of PSA was increased by the application of the $F / T$

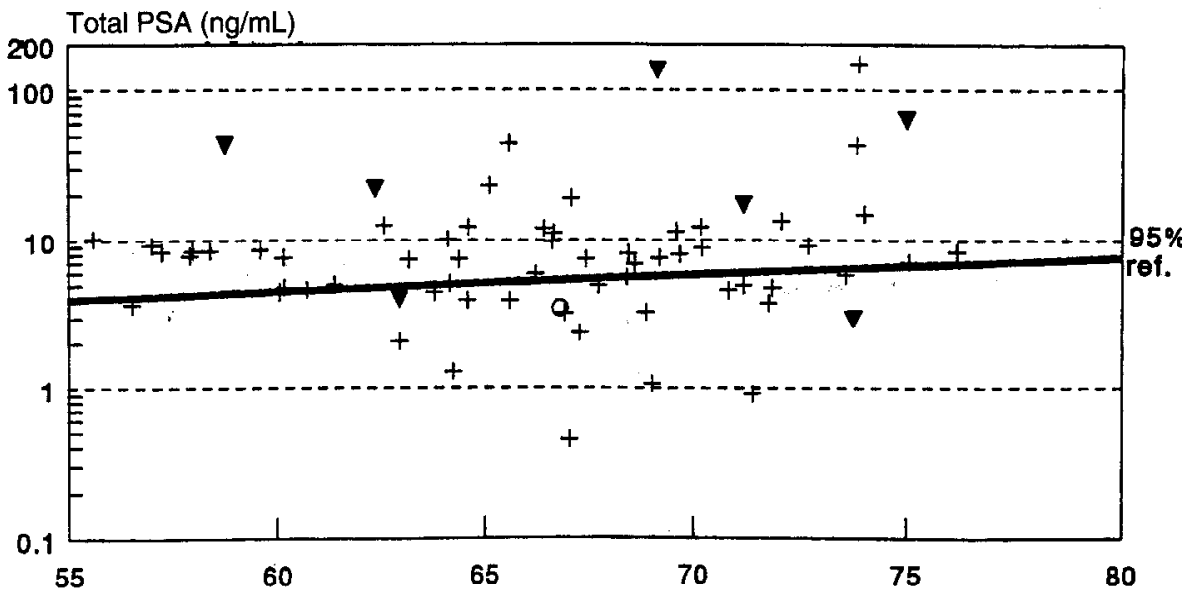

Age (years)
FIGURE 2. Relationship between total PSA and age of 67 men with prostate carcinoma; the age-specific reference range and clinical stage of 66 carcinomas are indicated. 


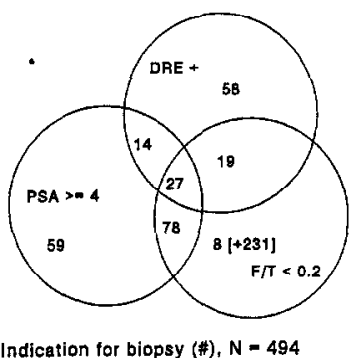

A

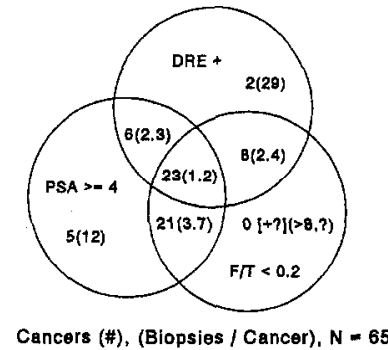

B
FIGURE 3. Venn diagrams showing simulated case selection for biopsy based on an abnormal digital rectal examination, a total serum PSA of $4.0 \mathrm{ng} / \mathrm{mL}$ or more, and a free to total serum PSA ratio of 0.20 or less; between brackets, the number of men selected but without biopsy is noted (A). The number of positive biopsy results and the biopsy/prostate cancer ratio (between parentheses) are depicted separately (B).

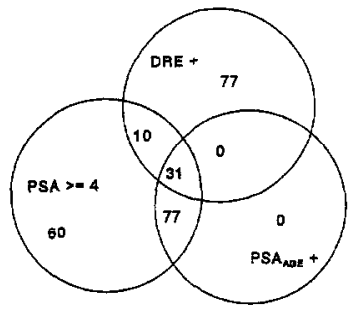

Indication for biopsy (\#), N - 255

A

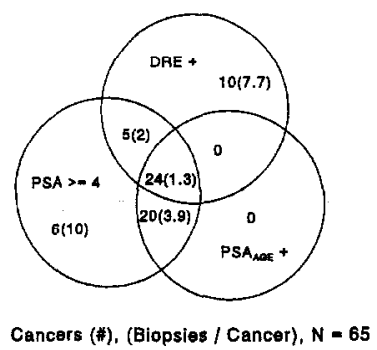

B
FIGURE 4. Venn diagrams showing simulated case selection for biopsy based on an abnormal digital rectal examination, a total serum PSA of $4.0 \mathrm{ng} / \mathrm{mL}$ or more, and a higher PSA value than the age-specific reference range; between brackets, the number of men selected but without biopsy is noted $(A)$. The number of positive biopsy results and the biopsy/prostate cancer ratio (between parentheses) are depicted separately (B).

ratio. Using the $F / T$ ratio instead of the total serum PSA as an indicator for biopsy in this PSA range, five cancers would not have been detected (Fig. 3B). The number of biopsies decreased from 308 (Fig. 1A) to 196 (Fig. 3A), a reduction of $37 \%$. The overall number of detected carcinomas decreased with $5+2=7(11 \%)$; the $\mathrm{Bx} / \mathrm{PC}$ ratio was reduced from 4.6 to 3.3 .

\section{AGE-SPECIFIC REFERENCE RANGES}

Figure 4 shows the simulation procedure using a PSA value of $4.0 \mathrm{ng} / \mathrm{mL}$ or more, an abnormal DRE, and age-specific PSA reference ranges as criteria for biopsy. There were 255 men entered into this simulation. No participants would have been selected for biopsy based only on the age-specific reference ranges, as all upper limits are above 4.0 $\mathrm{ng} / \mathrm{mL}$. There were 60 men selected for biopsy on the basis of a PSA of $4.0 \mathrm{ng} / \mathrm{mL}$ only (Fig. 4A). In this group, six carcinomas were detected (Fig. 4B).

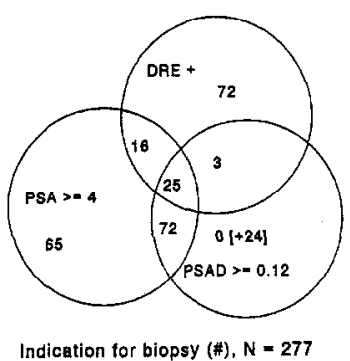

A

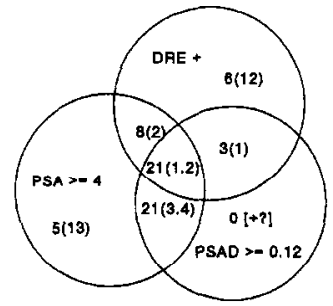

Cancers (\#), (Biopsies / Cancer), N - 64

B
FIGURE 5. Venn diagrams showing simulated case selection for biopsy based on an abnormal digital rectal examination, a total serum PSA of $4.0 \mathrm{ng} / \mathrm{mL}$ or more, and a PSA density of $0.12 \mathrm{ng} / \mathrm{mL} / \mathrm{cc}$ or more; between brackets, the number of men selected but without biopsy is noted $(A)$. The number of positive biopsy results and the biopsy/prostate cancer ratio (between parentheses) are depicted separately (B).

So, if only age-specific PSA reference ranges were used together with an abnormal DRE as indication for biopsy, six cancers would not have been detected. This would have limited the number of biopsies from 308 to 195 , a reduction of $37 \%$, with a $\mathrm{Bx} / \mathrm{PC}$ ratio dropping from 4.6 to 3.3. The omission of TRUS and the use of age-specific reference ranges would have induced a loss of $2+6=8$ (12\%) nonpalpable carcinomas. These eight cancers were organ confined.

\section{PSA DENSITY}

Figure 5 shows the simulated case selection for biopsy using a PSA value of $4.0 \mathrm{ng} / \mathrm{mL}$ or more, an abnormal DRE, and a PSA density of 0.12 $\mathrm{ng} / \mathrm{mL} / \mathrm{cc}$ or more as criteria for biopsy. Of the 277 men entered into this simulation, 253 had biopsies. In 66 of the 67 men with PC, the total prostate volume was measured; in 2 of them, cancer was detected only on the base of a hypoechogenic lesion. Therefore, 64 cancers were included in Figure 5R. Using PSAD and DRE as indicators for biopsy, a reduction in the number of biopsies from 308 to 212 was seen ( $28 \%$ ), and a loss of 2 $+5=7$ cancers $(11 \%)$.

If PSAD was used in the PSA range of $4.0 \mathrm{ng} / \mathrm{mL}$ or more, together with an abnormal DRE as indication for biopsy, five cancers would not have been detected (Fig. 5B). This would have limited the number of biopsies from 308 to 188 , a reduction of $39 \%$, with a $\mathrm{Bx} / \mathrm{PC}$ ratio dropping from 4.6 to 3.2. A loss of $2+5=7$ (11\%) unpalpable carcinomas would occur. These seven cancers were organ confined.

\section{PSA PRESCREEN}

Prescreening accounts for the selection of men before being submitted to screening for PC by various screening tools, with the possible result of 
being selected for biopsy. A prescreen PSA value of $2.0 \mathrm{ng} / \mathrm{mL}$ as a threshold for DRE and TRUS would give a $70 \%$ reduction in the number of TRUS investigations, at the price of $6 \%$ loss of cancers. The number of biopsies (on indication PSA $4.0 \mathrm{ng} / \mathrm{mL}$ or more, and/or abnormal DRE or TRUS) would be reduced by $30 \%$. If TRUS would also be omitted, screening of men with a serum PSA of $2.0 \mathrm{ng} / \mathrm{mL}$ or more with DRE would not detect $6 \%$ of cancers. The number of biopsies (on indication PSA $4.0 \mathrm{ng} / \mathrm{mL}$ or more or abnormal DRE, or both) would be reduced by $36 \%$.

\section{SumMaRY of SimUlation RESUlTS}

The main effects of the simulated case selection for biopsy are summarized in Table III. Significant differences between the various reductions of the number of biopsies were seen.

Concerning the loss of detected cancers, there was a significant difference between omitting TRUS and the various additions of parameters to improve the specificity of a PSA value of $4.0 \mathrm{ng} / \mathrm{mL}$ and more.

It was calculated that at least 100 carcinomas would be needed to obtain a significant difference between a loss of $6 \%$ and of $12 \%$ of cancers. ${ }^{19}$

\section{COMMENT}

In this screening population of 1726 men who all underwent total serum PSA measurement, DRE, and TRUS, most of the 67 carcinomas were found by sextant biopsies based on the indication of PSA or DRE, or both. Only two carcinomas were found by TRUS alone. The overall $\mathrm{Bx} / \mathrm{PC}$ ratio was 4.6.

The simulated case selections for biopsy are limited by the fact that all biopsies in the present study were taken on indication of total serum PSA, DRE, or TRUS. Data concerning additional parameters are never complete unless all participants of the study have biopsies. However, the simulation procedure reasonably illustrates what may happen to the sensitivity and specificity of a combination of tests for the detection of PC. The decrease in sensitivity has to be weighed against the increase in specificity.

The most cost-effective change of the present screening protocol would be to limit the number of TRUS procedures or to omit TRUS completely, as TRUS is the most time-consuming screening modality. A prescreen PSA value of $2.0 \mathrm{ng} / \mathrm{mL}$ as a threshold for DRE and TRUS would give a $70 \%$ reduction in the number of TRUS investigations, at the price of $6 \%$ loss of cancers. The number of biopsies (on indication of PSA $4.0 \mathrm{ng} / \mathrm{mL}$ or more or abnormal DRE, or both) would be reduced by $30 \%$. Screening all men by DRE and PSA only would reduce the number of biopsies by $17 \%$
(Fig. 1) with a loss of $3 \%$ of cancers and a $\mathrm{Bx} / \mathrm{PC}$ ratio of $255 / 65=3.9$.

Two parameters were discussed that may improve the specificity of the combination of total serum PSA with DRE without the use of TRUS. The most cost-effective is the application of agespecific PSA reference ranges. It was seen that this parameter decreases the sensitivity considerably: $12 \%$ of carcinomas would have been missed, and the number of biopsies were reduced by $37 \%$. This is at variance with the study of Oesterling et al. ${ }^{7}$ in which $5.5 \%$ of 1686 biopsies in an outpatient population of 2988 men of 60 years and older would have been avoided by the use of age-specific reference ranges, and 19 of the 608 cancers (3\%) would not have been detected. In the study of Catalona et al. ${ }^{5}$ who evaluated the effect of agespecific reference ranges in a screening study of 6630 men of 50 years and older, an overall reduction in the number of biopsies of $6 \%$ was obtained, with a loss of $8 \%$ of palpable and nonpalpable tumor detection. Both studies concern different study populations, without the use of TRUS for lesion detection.

The use of age-specific reference ranges as a prescreen value for application of DRE and TRUS has to be discouraged, as $39 \%$ of cancers would have been missed (Fig. 2). These findings are in line with our previous observations ${ }^{20}$ and those of Littrup et al., ${ }^{6}$ who found a loss of $28 \%$ of detectable cancers.

With a threshold of 0.20 , the application of the $\mathrm{F} / \mathrm{T}$ ratio would have induced a large number of additional biopsies, especially in the PSA range below $4.0 \mathrm{ng} / \mathrm{mL}$. The use of $\mathrm{F} / \mathrm{T}$ ratio for men with a total PSA of $4.0 \mathrm{ng} / \mathrm{mL}$ or more or an abnormal DRE would miss $11 \%$ of cancers and reduce the number of biopsies by $37 \%$. According to Colberg et al., ${ }^{21}$ there is a $7.9 \%$ incidence of carcinomas in the PSA range between 2.9 and 4.0 $\mathrm{ng} / \mathrm{mL}$. It can be estimated by extrapolation that in the 328 men with a PSA range of 2.0 to 4.0 $\mathrm{ng} / \mathrm{mL}$ in the present study 23 cancers would have been found by sextant routine biopsies, whereas actually 10 were detected. The value of the F/T ratio can be tested if one is willing to biopsy all men with a PSA of $2.0 \mathrm{ng} / \mathrm{mL}$ or more. The number of biopsies would increase from 308 to 506 , with an overall change of $\mathrm{Bx} / \mathrm{PC}$ ratio of 4.6 to an estimated $506 / 80=6.3$.

PSAD as an indicator for biopsy instead of a PSA value of $4.0 \mathrm{ng} / \mathrm{mL}$ or more, and in combination with DRE, has been reported to be more cost-effective than age-specific PSA reference values. ${ }^{6}$ In that evaluation of 2930 men recruited to a screening study, Littrup et al. ${ }^{6}$ recommended a "tailored biopsy approach" using PSAD with a threshold of $0.12 \mathrm{ng} / \mathrm{mL} / \mathrm{cc}$ in combination with 
DRE, in which the number of biopsies were reduced with $15.7 \%$ at the price of a loss of $3.6 \%$ of the cancers. In the present simulation, these numbers for the use of PSAD were larger, respectively, $28 \%$ and $11 \%$. The larger number of undetected carcinomas might be due to the included effect of omitting TRUS for lesion detection and the assumption that no cancers would have been detected by biopsies on the indication of PSAD only.

\section{CONCLUSIONS}

Minimal loss of cancer detection of $3 \%$ with a reduction in the number of biopsies of $17 \%$ is obtained when TRUS is omitted from a screening protocol in which a PSA value of $4.0 \mathrm{ng} / \mathrm{mL}$ and more, an abnormal DRE, or an abnormal TRUS are used as indicators for biopsy.

Age-specific PSA reference ranges, an $\mathrm{F} / \mathrm{T}$ ratio with a threshold of 0.20 , and a PSAD with a threshold of $0.12 \mathrm{ng} / \mathrm{mU} / \mathrm{cc}$ may all reduce the number of biopsies with approximately $35 \%$ in this study, with a reduction in cancer detection of $11 \%$.

The value of $F / T$ ratio for screening for $P C$ has not yet been assessed optimally: especially in the PSA range below $4.0 \mathrm{ng} / \mathrm{mL}$, a threshold needs to be established for discriminating between benign and malignant disease.

The most cost-effective protocol for screening PC appears to be prescreening by total serum PSA and exclusion of DRE and TRUS with PSA values of $2.0 \mathrm{ng} / \mathrm{mL}$ or less.

ACKNOWLEDGMENT. To our laboratory technicians Ineke Eman and Bianca E. den Hartog for their expert work.

\section{REFERENCES}

1. Mettlin C, Lee F, Drago J, and Murphy GP: The American Cancer Society National Prostate Cancer Detection Project, findings on the detection of early prostate cancer in 2425 men. Cancer 67: 2949-2958, 1991.

2. Brawer MK, Chetner MP, Beatie J, Buchner DM, Vessella RL, and Lange PH: Screening for prostatic carcinoma with prostate specific antigen. J Urol 147: 841-845, 1992.

3. Labrie F, Dupont A, Suburu R, Cusan L, Tremblay M, Gomez JL, and Emond J: Serum prostate specific antigen as pre-screening test for prostate cancer. J Urol 147: 846-852, 1992.

4. Kirkels WJ, Schröder FH, Damhuis RS, Nijs HG, and Roobol-Bouts M: A European study for screening of adenocarcinoma of the prostate. Report of a pilot study. J Urol 149 (suppl.): 289A, 1993

5. Catalona WJ, Richie JP, Ahmann FR, Hudson MA, Scardino PT, Flanigan RC, deKernion JB, Ratliff TL, Kavoussi LR, Dalkin BL, et al: Comparison of digital rectal examination and serum prostate specific antigen in early detection of prostate cancer: results of multicenter clinical trial of 6630 men. J Urol 151: 1283-1290, 1994.

6. Littrup PJ, Kane RA, Mettlin CJ, Murphy GP, Lee F, Toi A, Badalament R, and Babaian R: The investigators of the
American Cancer Society National Prostate Cancer Detection Project. Cost-effective Prostate Cancer Detection, reduction of low-yield biopsies. Cancer 74: 3146-3158, 1994.

7. Oesterling JE, Jacobsen SJ, and Cooner WH: Use of age-specific reference ranges for serum prostate specific antigen in men 60 years or older. J Urol 153: 1160-1163, 1995.

8. Babaian RJ, Kojima M, and Ramirez, EI: Prostate specific antigen density and age referenced PSA versus PSA alone in early detection of prostate cancer. J Urol 153: 761, 1995.

9. Catalona WJ, Smith DS Wolfert RL, Wang TJ, Rittenhouse HG, and Ratliff TL: Increased specificity of PSA screening through measurement of percent free PSA in serum. J Urol 153: $336,1995$.

10. Christensson A, Bjork T, Nilsson O, Dahlen U, Matikainen MT, Cockett AT, Abrahamsson P, and Lilja $\mathrm{H}$ : Serum prostate-specific antigen complexed to alpha-1antichymotrypsin as an indicator of prostate cancer. J Urol 150: 100-105, 1993.

11. Lilja H, Bjork T, Abrahamsson P, Stenman U, Shaw N, Dowell B, Oesterling J, Pettersson K, Piironen I, and Lovgren T: Improved separation between normals, benign prostatic hyperplasia (BPH), and carcinoma of the prostate (CAP) by measuring free $(F)$, complexed $(C)$ and total concentrations $(\mathrm{T})$ of prostate specific antigen (PSA). J Urol 151: 400A, 1994.

12. King C, Friese J, Lauren L, Dowell B, Shaw N, Lilja H, Stenman U, Piironen $T$, and Pettersson K: Measurement on IMx of free and total forms of prostate specific antigen for differentiation of patients with benign prostatic hyperplasia and prostate cancer. Clin Chem 40: 1007-1010, 1994.

13. Bangma $\mathrm{CH}$, Kranse R, Blijenberg BG, and Schröder $\mathrm{FH}$ : The value of screening tests in the detection of prostate cancer. 1. Results of a retrospective evaluation of 1726 men. Urology 46: 773-778, 1995.

14. Oesterling JE, Jacobsen SJ, Chute CG, Guess HA, Girman CJ, Panser LA, and Lieber MM: Serum prostate-specific antigen in a community-based population of healthy men: establishment of age-specific reference ranges. JAMA 270: 860-864, 1993.

15. Benson MC, Whang IS, Pantuck A, Ring K, Kaplan SA, Olsson CA, and Cooner WH: The use of prostate specific antigen density to enhance the predictive value of intermediate levels of serum prostate specific antigen. J Urol 147(3): 817-821, 1992.

16. Bangma $\mathrm{CH}$, Kranse R, Blijenberg BG, and Schröder FH: The new DELFIA prostate specific antigen (PSA) assays of free and total PSA: results of the first comparative evaluation (abstract 264). J Urol 153: 294A, 1995.

17. Blijenberg BG, Bangma $C H$, Kranse $R$, and Schröder FH: Analytical evaluation of the new DELFIA free and total prostate-specific antigen assays. 11th International European Congress of Clinical Chemistry, 1995, Tampere, Finland.

18. DeAntoni EP, Crawford ED, Stone NN, Blum DS, Bergr ER, Eisenberger MA, Gambert SR, and Staggers F: Prostate Cancer Awareness Week. 1992: a summary of key findings. Clin Invest Med 16: 448-457, 1993.

19. Brawer MK: Prostate specific antigen: critical issues. Urology 44: 9-17, 1994.

20. Nooter RI, Bangma $\mathrm{CH}$, and Schröder $\Gamma \mathrm{II}$ : Age-specific reference ranges for prostate-specific antigen. JAMA 271: 746-747, 1994.

21. Colberg JW, Smith DS, and Catalona WJ: Prevalence and pathological extent of prostate cancer in men with prostate specific antigen levels of 2.9 to $4.0 \mathrm{ng} / \mathrm{mL}$. J Urol 147: $507-509,1993$. 